\title{
ANÁLISE DA DINÂMICADE USO E COBERTURA DA TERRA NA REGIÃO METROPOLITANA DE NATAL NO PERÍODO DE 1984 A 2018
}

\author{
Ana Paula Frazão ${ }^{1}$ \\ Venerando Eustáquio Amaro ${ }^{2}$ \\ Silvio Braz de Sousa ${ }^{3}$
}

\section{Resumo}

Mapas de cobertura e uso da terra são importantes ferramentas de ordenamento territorial. Este estudo buscou compreender e quantificar o uso e a cobertura da terra na Região Metropolitana de Natal nos anos de 1984 e 2018, a partir de um processo de classificação supervisionada (algoritmo de Bhattacharya) de um compositie anual de imagens LANDSAT 5-TM e LANDSAT 8-OLI.Os resultados apontam que entre 1984 e 2018 (34 anos) ocorreu intensa e rápida conversão das áreas de vegetação (redução de $\sim 1.402 \mathrm{~km}^{2}$ ) e sua apropriação para atividades antrópicas, predominantemente agropecuária. Também se constatou um processo de urbanização bastante expressivo, registrando uma expansão urbana de $243 \%$. Nossos resultados corroboram com a observada sinergia entre dados orbitais da série LANDSAT e Rapideyee colabora para o entendimento que a metropolização de Natal foi institucional.

Palavras-Chaves: LANDSAT, Rapideye, expansão urbana

\section{ANALYSIS OF THE DYNAMICS OF LAND USE AND COVERAGE IN THE METROPOLITAN REGION OF NATAL IN THE PERIOD FROM 1984 TO 2018}

\begin{abstract}
Land use and cover maps are important tools for spatial planning. This research aimed to understand and quantify the land use and land cover in the Natal metropolitan area from 1984 - 2018. The data are based on a supervised classification process (Bhattacharya algorithm) of an annual LANDSAT 5-TM and LANDSAT images 8-OLI compositie. The results show that from 1984 to 2018 (34 years), the vegetation area has undergone drastic and rapid changes (depletion of $1,402 \mathrm{~km}^{2}$ ), and it is mainly used for anthropic activities such as agriculture. It is also verified a significant urbanization process, with an urban expansion of $\sim 243 \%$. Our findings are consistent with the synergy between the orbital data observed by the LANDSAT

\footnotetext{
${ }^{1}$ Mestranda em Geografia no Programa de Pós-Graduação e Pesquisa em Geografia da Universidade Federal do Rio Grande do Norte. Email: anapaulafazao123@gmail.com

${ }^{2}$ Professor titular do Departamento de Geologia da Universidade Federal do Rio Grande do Norte. Docente do Programa de Pesquisa e Pós-Graduação em Geodinâmica e Geofísica (PPGG/UFRN), Programa de Pós-graduação em Ciência e Engenharia do Petróleo (PPGCEP/UFRN) e do Programa de Pós-Graduação e Pesquisa em Geografia (PPGe/UFRN). E-mail: venerandoamaro@gmail.com

3 Professor Adjunto do Departamento de Geografia da Universidade Federal do Rio Grande do Norte (DGE/UFRN) e docente do Programa de Pós-Graduação e Pesquisa em Geografia (PPGe/UFRN). Email: sousasb@gmail.com
} 
and Rapideyee series, collaborating for the understanding that the metropolitanization of Natal was institutional.

Keywords: LANDSAT, Rapideye, urban expansion

\section{ANÁLISIS DE LA DINÁMICA DE USO Y COBERTURA DE LA TIERRA EN LA REGIÓN METROPOLITANA DE NATAL EN EL PERÍODO DE 1984 A 2018}

\section{Resumen}

Los mapas de cobertura y uso del suelo son herramientas importantes de planificación espacial. Este estudio buscó comprender y cuantificar el uso y la cobertura del suelo en la Región Metropolitana de Natal en los años 1984 y 2018, con base en un proceso de clasificación supervisado (algoritmo de Bhattacharya) de una composición anual de imágenes LANDSAT 5TM y LANDSAT 8-OLI . Los resultados muestran que entre 1984 y 2018 (34 años) hubo una intensa y rápida conversión de áreas de vegetación (reducción de $\sim 1,402$ km²) y su apropiación para actividades humanas, predominantemente agrícolas y ganaderas. También hubo un proceso de urbanización muy significativo, registrándose una expansión urbana de $~ 243 \%$. Nuestros resultados colaboran con la sinergia observada entre los datos orbitales de las series LANDSAT y Rapideye y contribuyen a entender que la metropolización de Natal fue institucional.

Palabras clave: LANDSAT, Rapideye, expansión urbana

\section{INTRODUÇÃO}

A urbanização em zonas costeiras, incluindo as áreas planas e baixas das bacias hidrográficas, tornou-se um símbolo do modelo de desenvolvimento estabelecido desde o século XX, em função das vantagens de sua localização geográfica (BARAU e LUDIN, 2012). De modo geral, as projeções das Nações Unidas (2004) sugerem que $66 \%$ da população mundial habitarão em áreas urbanas, o que causará pressão antropogência sem precedentes sobre a capacidade de suporte ambiental das grandes cidades pelo aumento na demanda de fluxo de recursos e, consequentemente, pela fragmentação na coexistência dos seus sistemas naturais e sociais, com redução na biodiversidade e depreciaçãodos benefícios naturais oferecidos pelos ecossistemas (DEWAN e YAMAGUCHI, 2009; LAI et al., 2015).

Diante dessas tendências, as cidades costeiras, com todos os benefícios de belezas paisagísticas, culturais, contemplativas, recreacionais e de acessos estratégicos, tornaram-se centros de atração para as atividades socioeconômicas, resultando em urbanizações e conurbações contínuas e crescentes que, consequentemente, promovem a ampliação 
FRAZÃO, Ana Paula

AMARO, Venerando Eustáquio

SOUSA, Silvio Braz de

demográfica e as rápidas mudanças no uso e cobertura da terra (ZHANG e SETO, 2011; CELLIERS e NTOMBELA, 2015).

Aproximadamente 3 bilhões de pessoas, cerca de metade da população mundial, viviam na faixa de terra de até $200 \mathrm{~km}$ do litoral, número previsto para dobrar até 2025 (CREEL, 2003).

No Brasil, as cidades costeiras comportam mais de $60 \%$ da população brasileira (PBMC, 2017) que é responsável pela geração de cerca de $30 \%$ de toda a riqueza nacional (IBGE, 2014).

O crescimento socioeconômico em regiões costeiras carecem, como ação basilar, do levantamento de conjuntos de dados espaciais e não espaciais em que os mapas de uso e cobertura da terra desempenham tarefa primordial na orientação das políticas de planejamento, no estabelecimento de estratégias de gestãoe nomonitoramento ambiental, desde os níveis regionais aoslocais (LONG et al., 2007).

As informação disponibilizadas nos mapas de uso e cobertura da terra compõem um significativo instrumento de avaliação dos potenciais impactos negativos sobre a intervenção antrópica nas unidades geoambientais costeiras, tipicamente compostas por características físicas que denotamalta fragilidade natural, permitindo uma melhor compreensão das dinâmicas de substituição dos aspectos naturais dessas feiçoes pela expansão urbana (áreas residenciais ou comerciais), atividades econômicas e suas infraestruturas relacionadas (LOPEZ et al., 2001; LAI et al., 2015).

A urbanização é uma das causas antropogênicas apregoadas como responsáveis pelo declínio da cobertura vegetal natural (AMATO-LOURENÇO et al., 2016), perda de terras aráveis (LOPEZ et al., 2001) e destruição de habitats e redução de biodiversidades, sobretudo em zonas costeiras (ALPHAN, 2003; LAI et al., 2015; CELLIERS e NTOMBELA, 2015). Assim, estudos sobre o uso e cobertura da terra são particularmente importantes porque as características de alterações espaço-temporais são úteis nacompreensãode diversos impactos das atividades humanas sobre as condições ecossistêmicas do ambiente urbano e seu entorno (YEH e LI, 1999).

Mudanças aceleradas no uso e cobertura da terra, em função de extensivas atividades socioeconômicas, têm ocorrido nos países em desenvolvimento, quando comparados aos países desenvolvidos, refletindo projeções de que até o ano de 2030 cerca de 400 milhões de pessoas estarão concentradas em 23 megalópoles instaladas em zonas costeiras, a maioria 
nos países em desenvolvimento (BANCO MUNDIAL, 2007; LE, 2020).

Neste contexto, os termos de uso da terra e cobertura da terra são frequentemente usados de forma intercambiável guardando, contudo, significados específicos: a cobertura da terra refere-se à cobertura superficial no solo como vegetação, infraestrutura urbana, água, solo exposto, entre outros; o uso da terra refere-se ao propósito ao qual o espaço atende, por exemplo, recreação, habitat da vida selvagem ou agricultura. $\mathrm{O}$ emprego integrado em uso da terra/cobertura da terra refere-se à categorização de atividades humanas e de elementos naturais na paisagem, condizente com determiinado período de tempo e realizadocom o emprego de materiais e métodos científicos e estatísticos adequados a uma determinada escala espaço-temporal (SINGH, 2015).

Diante de cenários futuros de crescentes urbanizações e conurbações em zonas costeiras no mundo e no Brasil, com tendências de amplificação de adversidades decorrentes das limitações de território com alta fragilidade natural e diantedo enfrentamento às mudanças do clima (PBMC, 2016), são imprescindíveis políticas de planejamento e gestão do uso da terra que integrem os municípios costeiros numa governança metropolitana colaborativa na execução de funções públicas de interesse comum (MELCHIORS e CAMPOS, 2016).

A Constituição Federal de 1988 descentralizou a gestão urbana facultando aos estados a instituição de Regiões Metropolitanas, que passam a ser criadas por lei complementar estadual e com autonomia dos municípios interessados, em anuência aos interesses de cada estado na resolução de adversidades urbanas, como as estratégias no gerenciamento do uso da terra e dos serviços urbanos (OBSERVATÓRIO DAS METRÓPOLES, 2009).

A Região Metropolitana de Natal (RMN) foi criada por Lei Complementar Estadual nº152 de 16/01/1997, acompanhando um segundo período (década de 1980 à década de 1990) de governança metropolitana baseada em modelos e arranjos estabelecidos sob a influência da promulgação da Constituição de 1988 e permaneceu em recomposição no terceiro período (a partir dos anos 2000), com a reintegração das questões metropolitanas na agenda política do país (FERNANDES e ARAÚJO, 2015; MELCHIORS e CAMPOS, 2016). Atualmente, na RMN constam 15 municípios: aqueles designados em 1997, Natal, Parnamirim, São Gonçalo do Amarante, Ceará-Mirim, Extremoz, Macaíba, todos designados em 1997; Nísia Floresta e São José de Mipibu, integrados em 2002; Monte Alegre incorporado em 2005; Vera Cruz em 2009; Maxaranguape em 2013; Arês, Goianinha 
FRAZÃO, Ana Paula

AMARO, Venerando Eustáquio

SOUSA, Silvio Braz de

e Ielmo Marinho todos incluídos em 2015; e, Bom Jesus integrado em 2019. Apesar de Natal, capital do Estado do Rio Grande do Norte $(\mathrm{RN})$, ser a segunda menor capital do país em área territorial, a RMN é a quarta maior do Nordeste (IBGE, 2015).

A RMN enfrenta problemas quanto aos processos de ocupação das terras, similares às demais regiões metropolitanas do país, onde cerca de 10,13\% da população do Município de Natal reside em favelas e loteamentos irregulares (IBGE, 2010). Tais ocupações estão instaladas sobretudo, em áreas de preservação ambiental como, por exemplo, 33,3\% em campos de dunas, 17,4\% em manguezais e 5,8\% encostas de falésias e dunas (GROSTEIN, 2001), realidade ainda persistente.

Diante dos desafios da gestão do uso da terra, das políticas e estratégias integradas de planejamento deficitárias ou ausentes, com a crescente demanda dos municípios participantes da RMN por atuação conjunta na resolução das questões territoriais, e das inovações geotecnológicas, conta-se que a análise comparativa espaço-temporal de mapas de uso e cobertura da terra auxiliem na gestão territorial. Desse modo, busca-se melhor desempenho no gerenciamento do uso dos recursos naturais e no planejamento de políticas públicas, a exemplo de outras regiões similares pelo mundo (YIN et al., 2010; ZANG e SETO, 2011; MENDOZA et al., 2011; SINGH, 2015; SANHOUSE-GARCIA, et al., 2017, AMARO et al., 2021).

Este artigo pretende fazer o mapeamento e a análise comparativa do uso e cobertura da terra na RMN nos anos de 1984e 2018, com base em imagens de Sensoriamento Remoto e no emprego de técnicas de Geoprocessamento na validação de dados geoespacias em SIG. A escolha do ano de 1984 foi motivada para servir de referência das condições de uso e cobertura da terra antes da implementação da RMN.

Portanto, conta-se com os mapas de dados geoespaciais da dinâmica de uso da terra, que perfazem operíodo de 34 anos, no debate ambiental e territorial quanto à expansão urbana em áreas frequentemente inapropriadas, à substituição de classes naturais por antrópicas, com o consequente desmatamento e ameaças aos mananciais de abastecimento hídrico para a população em crescimento na RMN.

\section{ÁREA DE ESTUDO}

A RMN ocupa área total de $3.678 \mathrm{~km}^{2}$ localizada na zona costeira oriental do RN (Figura 1) congregando população total atual estimada em 1.614.227 habitantes (IBGE, 2019), o dobro 
da população de cerca de 805.000 habitantes dos primeiros municípios que integravam a RMN nos anos 80 .

Figura 1. Mapa de localização da Região Metropolitana de Natal
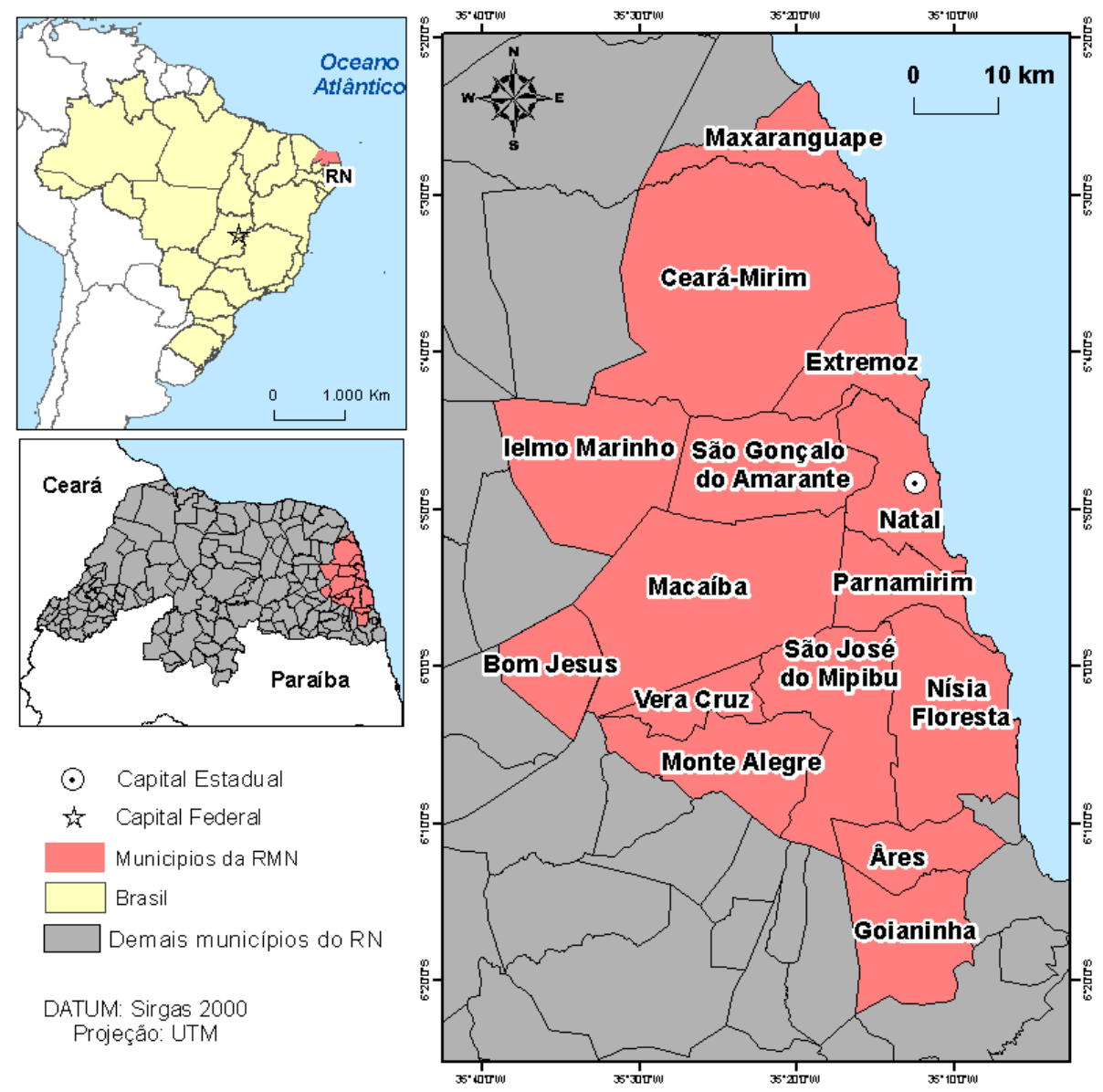

Fonte: Elaboração autores

O contexto climático desse cinturão costeiro possui clima tropical de verão secodo tipo As na classificação de Köppen, com, com temperatura média anual de $26,8^{\circ} \mathrm{C}$ e precipitaçãomédia de $1380 \mathrm{~mm} /$ ano concentrada naestação chuvosa entre os meses de abril a julho (ALVARES et al., 2013; INMET, 2020). É importante resaltar que boa parte dos seus municípios estão em zonas costeiras.

As atividade industriais estão distribuidas nos municípios de Macaíba, Parnamirim, São Gonçalo do Amarante e Extremoz, como também as atividades turísticas nos municípios de Extremoz (Praia de Genipabu), Natal e Nisia Floresta (setor de praias da Rota do Sol) . Entretanto, na estrutura produtiva regional o peso recai nas atividades terciárias, comércio varejista e atacadista, e atividades de serviço públicos e privados. Pessoa (2012), afirma que é 
FRAZÃO, Ana Paula

AMARO, Venerando Eustáquio

SOUSA, Silvio Braz de

necessário ainda um maior processo de integração e definição de políticas e ações econômicas integradas entre os municípios da RMN.

A constituição da RMN teve a finalidade de executar funções públicas que, por sua natureza, exigem a cooperação para a solução de problemas comuns, no atendimento às necessidades da população aos serviços de saneamento básico e de transporte coletivo, o que legitimariasua existência, em termos políticos-institucionais, além de permitir uma atuação mais integrada do poder público (IBGE, 2010).

\section{PROCEDIMENTOS METODOLÓGICOS}

No fluxograma esquemático da Figura 2 foram apresentados os procedimentos metodológicos subdividios nas etapas desde aaquisição de dados censitários, estatíticos e imagens multiespectrais de satélite (Etapa 1), Processamento Digital de Imagens em SIG (Etapa 2), validação da acurácia dos dados geoespaciais (Etapa 3) e elaboração dos mapas de uso e cobertura da terra para os anos de 1984 e 2018.

Figura 2. Fluxograma de procedimentos metodológicos

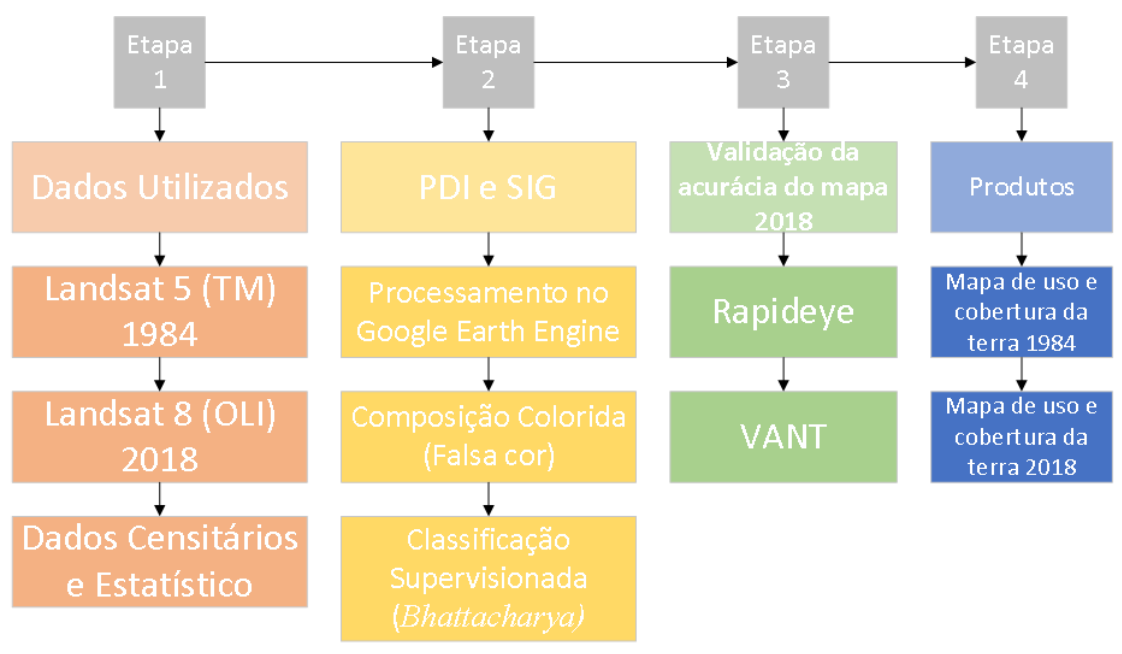

Fonte: Elaboração autores

\section{Dados Estatísticos e Censitários}

Dados estatísticos e censitários adquiridos gratuitamente do Instituto Brasileiro de Gografia e Estatística (IBGE, https://sidra.ibge.gov.br), e utilizados em conjunto com os dados geoespaciais na análise do crescimento urbano, populacional e dos aspectos de uso da 
terra na RMN. Os dados anuais do IBGE correspondem ao Censo Agropecuário, a Produção Agrícola Municipal e a Pesquisa Pecuária Municipal.

Além disso, dados estatísticos disponíveis no portal do Instituto de Pesquisas Econômicas Aplicadas (IPEA, http://www.ipeadata.gov.br/) foram utilizados para comparar a extensão das áreas de pastagem e agricultura levantadas pelo Censo Agropecuário em 2017 e as mesmas classes mapeadas neste estudo para o ano de 2018.

\section{Imagens Multiespectrais de Sensoriamento Remoto}

A elaboração do mapas de uso e cobertura da terra da RMN nos anos de 1984 e 2018 foram baseados na análise e interpretação de imagens multiespectrais das faixas do visívelinfravermelho próximo do satélite LANDSAT 5, sensor Thematic Mapper (TM), para o ano de 1984, e para o ano de 2018 imagens do satélite LANDSAT 8, sensor Operational Land Imager (OLI), ambas com resolução espacial de 30m. Tais imagens da série LANDSAT (World wide Reference System de órbitas/pontos 214/64 e 215/64) foram obtidos gratuitamente e online do Serviço Geológico dos Estados Unidos (USGS, https://earthexplorer.usgs.gov/).

As imagens para cada ano foram transformados em composite anual pixel a pixel, onde os pixels com nuvens são reclassificas conforme o algoritmo de processamento de nuvens do Google Earth Engine (https://earthengine.google.com/).

\section{Processamento Digital de Imagen e Sistemas de Informações Geográficas}

Os mapas de uso e cobertura para a RMN nos anos de 1984 e 2018 foram elaborados em ambiente SIG, com abordagem baseada na classificação supervisionada com o algoritmo Bhattacharya e limiar de aceitação de 95\%. Que é um classificador supervisionado por regiões, que utiliza a distância Bhattacharya para medir a separabilidade estatística entre cada par de classes espectrais. Nesta etapa, foram adotadas todas as bandas do espectro refletido disponíveis em cada sensor (TM e OLI).

Na etapa de pós-classificação foi usada a filtragem de pixels isolados a partir da análise da vizinhança imediata do pixel analisado, admitindo um número de filtragem até 10 pixels agrupados para as imagens com resolução de 30m da série LANDSAT. Em seguida foi aplicado um filtro de maioria de matriz $21 \times 21$ pixels e peso 1 para o pixel central, reclassificando os pixels para a classe predominante na vizinhança. 
FRAZÃO, Ana Paula

AMARO, Venerando Eustáquio

SOUSA, Silvio Braz de

No processo de inspeção visual e vetorização em ambiente SIG foram adotadas diversas composições coloridas falsa cor e cor verdadeira para interpetar um universo de sete classes principais de uso e cobertura da terra, representativas das práticas adotadas na área de estudo, que foram: Agricultura, Pastagem, Mancha Urbana, Vegetação, Mosaico de Ocupação (que representam pequenas áreas com multiplos usos de caráter antrópico) e Água.

\section{Validação da Acurácia dos Mapas de Uso e Cobertura da Terra}

$\mathrm{Na}$ validação da acurácia dos mapas de uso e cobertura da terra foi utilizada como referência a imagem de 2018 doLANDSAT 8-OLI, submetidas ao ajuste com os seguintes tipos de dados: geoposicionamento coletados em campo; cerca de 200 pontos aleatórios por meio digital e bem distribuidos sobre imagem de Sensoriamento Remoto orbital do Rapideye, de 2020 que possui resolução espacial de $5 \mathrm{~m}$ e é disponibilizada gratuitamente pelo Ministerio de Clima e Meio Ambiente da Noruega (https://www.planet.com/); e, com 150 pontos aleatórios e bem distribuidos sobre oito ortofotomosaicos obtidos Veículos Aéreos Não Tripulados (VANT) com Ground Sample Distance (GSD) de $10 \mathrm{~cm}$, devoos foram realizados no ano de 2019 pelo Laboratório de Processamento de Dados e Gestão Territorial da Universidade Federal do Rio Grande do Norte (LAPROTER/UFRN) em diversos setores da RMN.

Metodologia similar de validação de acurácia de imagens da série LANDSAT tem sido empregada pelo Projeto MAPBIOMAS ${ }^{4}$, que é atualmente mais amplo mapeamento espaço-temporal de uso e cobertura da terra de biomas brasileiros.

\section{RESULTADOS E DISCUSSÃO}

A análise dos mapas de uso e cobertura da terra para os anos de 1984 e 2018 (Figura 3), mesmo em inspeção visual, indica que nesse período houve um amplo processo de expansão urbana e das atividades agrícolas e pastoris, com consequente desmatamento da cobertura vegetal natural no contexto dos municípios componente da RMN. A redução significativa registrada no conjunto da área ocupada por cobertura vegetal foi de $1.402,0 \mathrm{~km}^{2}$, o que representou perda de 51,75\% (Tabela 1 e 2), com destaque para os municípios de Macaíba, Ceara Mirim e Nísia Floresta, que juntos somam a diminuição de 504 km². Já no ano de 2018

\footnotetext{
${ }^{4}$ A metodologia incorporada pelo MAPBIOMAS está disponível em: https://mapbiomas.org/visao-geral-dametodologia.
} 
os municípios que possuem maior conservação da cobertura vegetal, são Ceará-Mirim com área de $320 \mathrm{~km}^{2}$ (24,7\%), Ielmo Marinho com 152 km² (12,4\%) e Macaíba com 145 km² (11,8\%). É importante resaltar que Ceará-Mirim e Macaíba são os municipios de maior extensão territorial, por isso se destacam em tantas clases de uso e cobertura.

As áreas de pastagens constituem a classe antrópica predominante na RMN nos anos mapeados (1984 e 2018), ocupando área total de $1.073 \mathrm{~km}^{2}$ em 2018, ou cerca de $29 \%$ da área total mapeada (Tabela 1), tendo uma área similar a ocupada por vegetação $\left(1.307 \mathrm{~km}^{2}\right)$. A área ocupada por agricultura também apresentou crescimento significativo de $550,5 \mathrm{~km}^{2}$ no período dos 34 anos analisado, registrando uma extensão ocupada de $766 \mathrm{~km}^{2}$ no ano de 2018, equivalente a $21 \%$ da área total da RMN. Portanto, a ocupação antrópica, de agricultura e pastagens são predominentes em 2018, somando 49,9\%, correpondendo a $1.836 \mathrm{~km}^{2}$, sendo $29,9 \%$ a mais que no ano de 1984. No período, aclasse mosaica de ocupação, usada em mapeamentos de uso e cobertura da terra em escalas pequenas e moderadas, registrou crescimento de cerca de $58,0 \mathrm{~km}^{2}$.

Figura 3. Mapas de uso e cobertura da terra da RMN nos anos de 1984 e 2018.
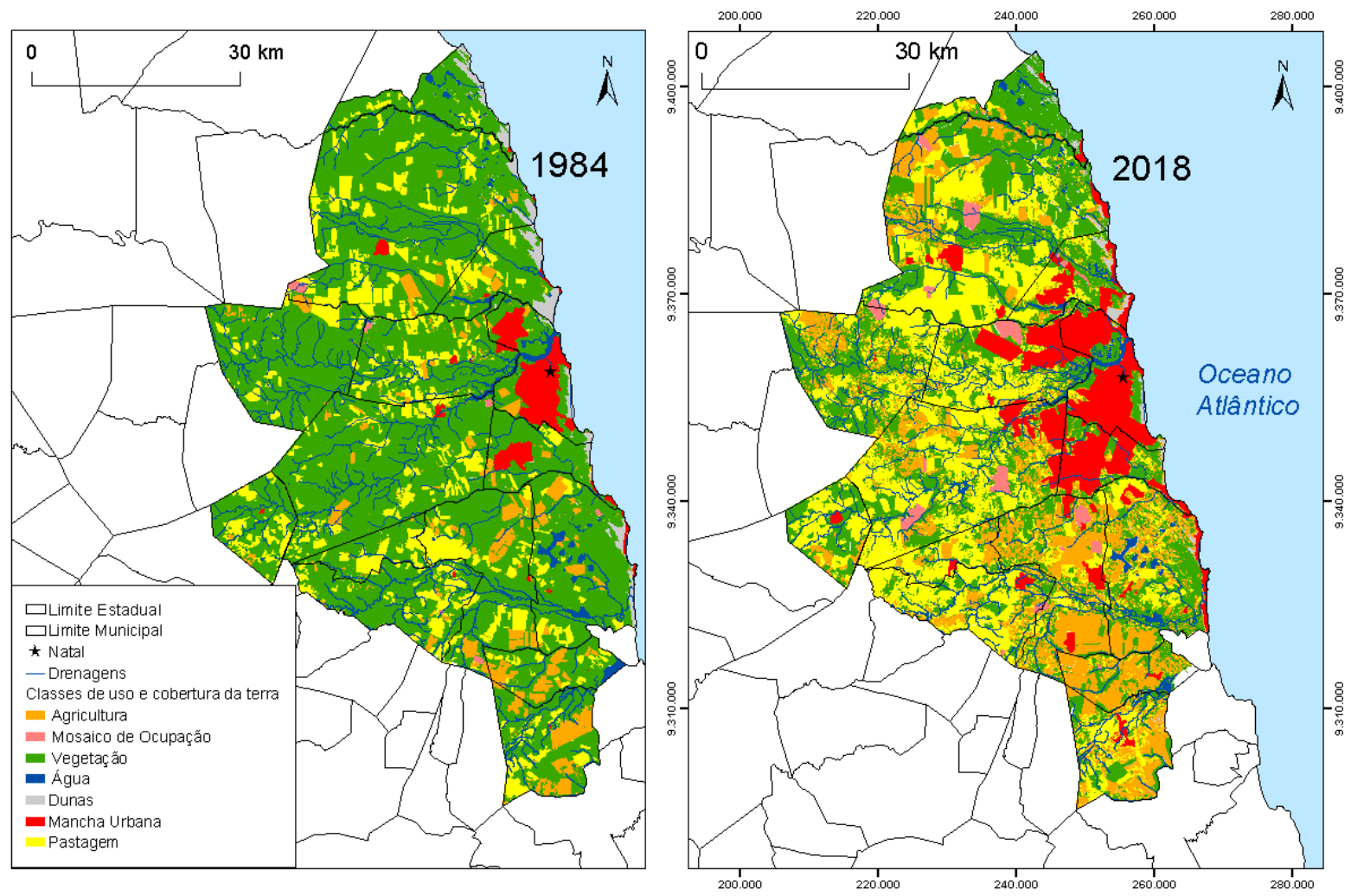

Fonte: Elaboração autores 
FRAZÃO, Ana Paula

AMARO, Venerando Eustáquio

SOUSA, Silvio Braz de

Tabela 1. Quantificação do uso e cobertura da terra da RMN nos anos de 1984 e 2018

\begin{tabular}{|c|c|c|c|c|c|c|}
\hline \multirow[b]{2}{*}{ Classes } & \multicolumn{2}{|c|}{1984} & \multicolumn{2}{|c|}{2018} & \multirow[t]{2}{*}{$\begin{array}{c}\begin{array}{c}\text { Mudança } \\
(\mathrm{km} 2)\end{array} \\
\end{array}$} & \multirow[t]{2}{*}{$\begin{array}{l}\text { Mudança } \\
\text { Relativa (\%) } \\
\end{array}$} \\
\hline & $\mathbf{k m}^{2}$ & $\%$ & $\mathbf{k m}^{2}$ & $\%$ & & \\
\hline Agricultura & 215,5 & 5,9 & 766 & 20,8 & 550,5 & 255,45 \\
\hline Água & 57,2 & 1,6 & 62,5 & 1,7 & 5,3 & 9,3 \\
\hline Dunas & 61,4 & 1,7 & 33,4 & 0,9 & -28 & $-45,6$ \\
\hline Mancha Urbana & 112,8 & 3,1 & 389 & 10,5 & 276,2 & 243,3 \\
\hline $\begin{array}{l}\text { Mosaico de } \\
\text { Ocupação }\end{array}$ & 8,2 & 0,2 & 58 & 1,6 & 50 & 533 \\
\hline Pastagem & 519,7 & 14,1 & $1.072,80$ & 29,1 & 553,1 & 106,42 \\
\hline Vegetação & 2.709 & 73,5 & 1307 & 35,4 & $-1.402,00$ & $-51,75$ \\
\hline total: & $3.695,50$ & 100 & $3.695,50$ & 100 & - & - \\
\hline
\end{tabular}

Fonte: elaboração autores

As pastagens em 2018 concentram-se nos municípios de Ceará-Mirim e Macaíba (Tabelas 2 e 3), que totalizam $461 \mathrm{~km}^{2}$ de áreas ocupadas, correspondendo a 40,19\% das pastagens da RMN. Esta informação está coerente com os números de cabeças bovinas estimados pelo IBGE (2018), onde Ceará-Mirim ocorre com o maior rebanho em cerca de 18.296 cabeças, que corresponde a lotação aproximada de 1,3 cabeças bovinas por hectare.

Os municípios com maior extensão de áreas cultivadas foram São José do Mipibu e Ceará-Mirim, cobrindo conjuntamente $256 \mathrm{~km}^{2}$, cerca de 33,4\% da áreade agricultura na RMN.

No período de 34 anos, a classe referente a água aumentou em 9,3\%. Em 2018 a maior concentração ocorre no Município de Nísia Floresta, que agrega 29,2\% de toda a água da RMN, baseada em lagoas como Arituba, Bonfim e Carcará, mananciais de abastecimento hídrico e pontos turisticos da RMN. No mapa de uso e cobertura da terra em 2018,destaca-se intensa ocupação antrópica nas margens dessas lagoas, e de outras da região, como por exemplo, na Lagoa do Bonfim, a maior da RMN, possui diversos tipos de ocupação, observando-se $3 \mathrm{~km}^{2}$ em volta a lagoa, calculou-se um total de $10,57 \mathrm{~km}^{2}$ e extensão de área cultivada, principalmente com cana-de-açúcar, cobrindo boa parte das áreas próximas, além disso, possui $9 \mathrm{~km}^{2}$ de pastagem, 2,65 km² de mosaico de ocupação e dois condomínios fechados ocupando a área de $2,2 \mathrm{~km}^{2}$.

Os setores ocupados por dunas móveis naturais mostraram redução de 45,6\% entre os anos de 1984 e 2018, redução equivalente a 28 km² (Tabela 1) em decorrência da conversão da área de dunas móveis em mancha urbana, o que configura o uso inadequado da terra, principalmente quanto as limitações desses terrenos às infraestruturas urbanas e saneamento básico necessários ao atendimento satisfatório da população instalada. Por exemplo, a 
expansão urbana da Zona Norte de Natal e Município de Extremoz, afetou o ambiente onde estão as dunas de Genipabu, referência turística para o RN, sobretudo devido à ocupação com loteamentos irregulares, redução do processo de realimentação com sedimentos das dunas pela interrupação no contato com as praias arenosas da região.

A expansão urbana total entre 1984 e 2018 foi de $276 \mathrm{~km}^{2}$ conduzida, sobretudo nos municípios de Natal, Parnamirim, Extremoz e São Gonçalo do Amarante, que juntos cresceram $177 \mathrm{~km}^{2}$. Dessa forma, a mancha urbana da RMN foi subdividia em dois grupos, aqueles da conurbação da cidade de Natal e os demais. Os municípios de Parnamirim, São Gonçalo do Amarante, Extremoz e Macaíba, que são limítrofes a Natal, possuem as maiores manchas urbanas em 2018 totalizando $313,72 \mathrm{~km}^{2}$, ou 81,83\% de toda área urbana da RMN(Tabela 2). Esses municípios também registraram expansão urbana de $213 \mathrm{~km}^{2}$ no período de 34 anos, correspondendo a cerca de 78,11\% da expansão urbana mapeada. Os demais dez municípios, de expressão urbana substancialmente menor, Vera Cruz com apenas $84,79 \mathrm{~km}^{2}$, possui a menor mancha urbana da RMN de apenas $1,58 \mathrm{~km}^{2}$. Porém se destaca os Nísia Floresta e Ceara-Mirim , por possuírem as maiores manchas urbanas dos municípios não limítrofes com a capital, equivalendo a $35,19 \mathrm{~km}^{2}$.

Tabela 2. Mancha Urbana e crescimento por $\mathrm{km}^{2}$ por município da RMN

\begin{tabular}{lrccc}
\hline Município & 1984 & 2018 & $\begin{array}{l}\text { Mudança( } \\
\left.\mathrm{km}^{2}\right)\end{array}$ & $\begin{array}{l}\text { Mudança } \\
\text { Relativa } \\
(\%)\end{array}$ \\
\hline Arês & 0,03 & 1,38 & 1,35 & 4500 \\
Ceará-Mirin & 4,5 & 18,58 & 14,1 & 312,8 \\
Parnamirim & 18,01 & 72,13 & 54,12 & 300,4 \\
Extremoz & 1,88 & 32,51 & 30,63 & $1.628,70$ \\
Goianinha & 0,22 & 5,31 & 5,09 & $2.218,20$ \\
Ielmo Marinho & 0,02 & 0,6 & 0,58 & 2.900 \\
Macaíba & 2,31 & 39,22 & 36,91 & $1.597,80$ \\
Maxaraguape & 0,32 & 2,88 & 2,56 & 800 \\
Monte Alegre & 0,46 & 4,47 & 4,01 & 871 \\
Natal & 77,36 & 116,38 & 42,02 & 50,4 \\
Nísia Floresta & 2,91 & 16,61 & 13,7 & 470,8 \\
São Gonçalo do Amarante & 3,48 & 53,48 & 50 & $1.436,80$ \\
São José do Mipibu & 0,57 & 15,81 & 15,24 & $2.673,70$ \\
Vera Cruz & 0,4 & 1,58 & 1,18 & 295 \\
Bom Jesus & 0,35 & 2,44 & 2,1 & 597,1 \\
Total & 112,84 & 383,38 & 273,59 & - \\
\hline
\end{tabular}

Fonte: Elaboração autores 
A mancha urbana de Natal possui a maior extensão da RMN e registrou em 2018 área aproximada de $116 \mathrm{~km}^{2}$, crescimento de $42 \mathrm{~km}^{2}$ em relação a área ocupada em1984. As análises da dinâmica nos mapas de uso da terra igualmente registraram municípios submetidos a intenso processo de urbanização, sobretudo pela proximidade com Natal e por comportarem serviços de suporte urbano à capital do RN, tais como: Parnamirim cuja mancha urbana em 1984 era de aproximadamente $18 \mathrm{~km}^{2}$ e de $72,13 \mathrm{~km}^{2}$ em 2018, aumento de $400 \%$ no período analisado (Tabela 2); Macaíba com mancha urbana de 39,22 km² em 2018 e 2,31 km² em 1984, contabilizando aumento significativo de 1.597\%; São Gonçalo do Amarante que registrou aumento na mancha urbana de $1.436 \%$, com extensão em $2018 \mathrm{de} 53 \mathrm{~km}^{2}$, e que sofre o processo de ampliação da urbanização, com a intensificação na comercialização de imóveis e novos loteamentos (Figura 4) decorrente da atração promovida pelo Aeroporto Internacional de Natal ali instalado em 2014, indicando uma situação favorável ao parcelamento urbano desse município; Goianinha, distante cerca de $52 \mathrm{~km}$ de Natal, mesmo registrando mancha urbana de 5,3 $\mathrm{km}^{2}$ em 2018, ou cerca de 1,4\% da mancha urbana total da RMN, expressivamente menor que os demais municípios, destacou-se com aumento de $2.218 \%$, aparentemente corresponde a cenário promovido pelo incremento das atividades turísticas e ofertas por loteamentos nessa região. Ielmo Marinho possui situação semelhante, pois seu crescimento foi o menor de toda $\mathrm{RMN}$, equivalente a $0,56 \mathrm{~km}^{2}$ só que sua mudança relativa foi de $2.900 \%$.

Figura 4. Anúncios de lotes em São Gonçalo do Amarante

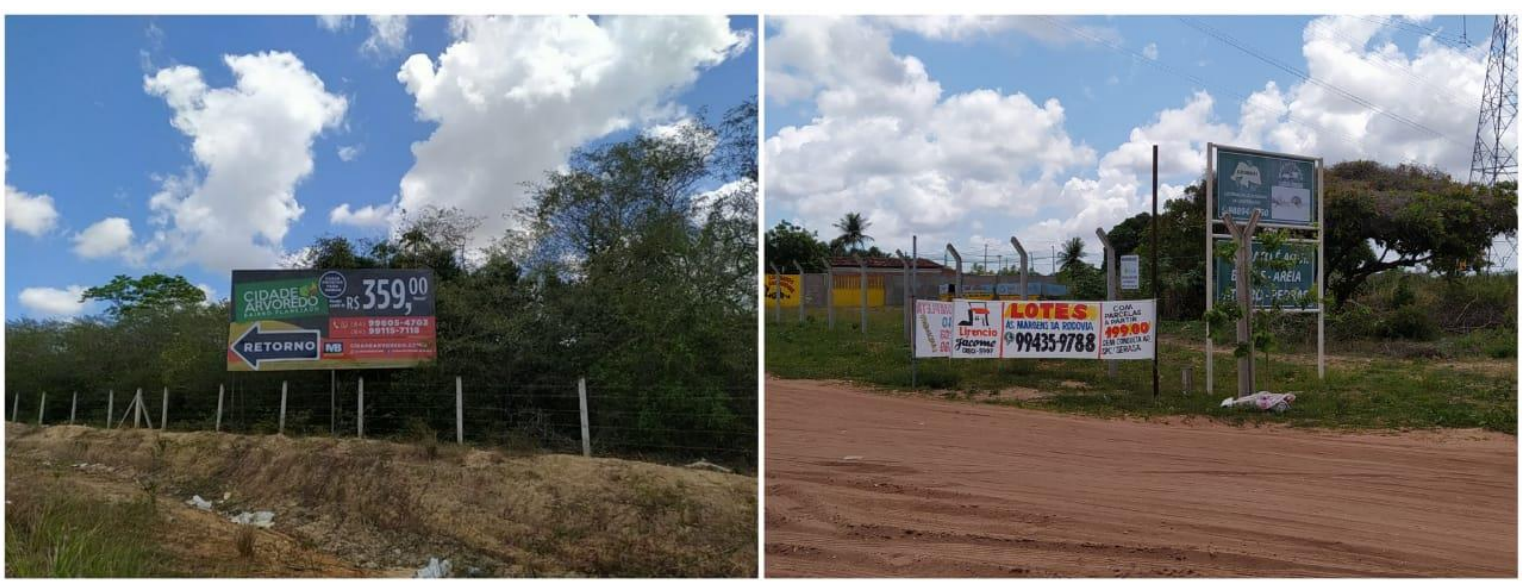

Fonte: Elaboração autores

Diante disso, destaca-se o fato que os municípios de Ielmo Marinho, Vera Cruz e Goianinha ainda não possuem Planos Diretores, conforme o Estatuto das Cidade (Lei Federal 
de $n^{\circ} 10.257$ de 10/06/2001) que tornou obrigatório que todas as cidades de uma Região Metropolitana tenham Planos Diretores, paralisados por falta de recursos. O Município de Ielmo Marinho tem o Plano Diretor em discussão na Câmera Municipal, enquanto Natal, Macaíba, São Gonçalo e Parnamirim estão em processo de revisão desses instrumentos.

Tabela 3. Quantificação por município das classes de uso e cobertura da terra da RMN $2018\left(\mathrm{~km}^{2}\right)$

\begin{tabular}{|c|c|c|c|c|c|c|c|}
\hline Município & Agricultura & Água & Dunas & $\begin{array}{c}\text { Mancha } \\
\text { Urbana }\end{array}$ & $\begin{array}{c}\text { Mosaico de } \\
\text { Ocupação }\end{array}$ & Pastagem & Vegetação \\
\hline & \multicolumn{7}{|c|}{$\mathrm{km}^{2}$} \\
\hline Arês & 66,61 & 4,40 & 0,03 & 1,38 & 0,27 & 5,95 & 32,33 \\
\hline Ceará-Mirim & 116,98 & 4,09 & 5,65 & 18,58 & 15 & 245 & 320 \\
\hline Parnamirim & 10,45 & 0,09 & 1,19 & 72,13 & - & 5,99 & 33,30 \\
\hline Extremoz & 11,48 & 3,97 & 8,48 & 32,51 & 2,02 & 28,47 & 52,75 \\
\hline Goianinha & 74,74 & 1,12 & 1,21 & 5,31 & - & 57,65 & 51,51 \\
\hline Ielmo Marinho & 62,74 & 0,95 & 0,20 & 0,60 & 3,38 & 91,91 & 152,58 \\
\hline Macaíba & 86,95 & 6,28 & 1,04 & 39,22 & 15,96 & 216,59 & 145,05 \\
\hline Maxaranguape & 10,37 & 4,40 & 5,76 & 2,88 & 0,30 & 14,24 & 92,56 \\
\hline Monte Alegre & 36,15 & 0,56 & 0,25 & 4,47 & 1,54 & 118,01 & 50,15 \\
\hline Natal & 4,77 & 9,25 & 3,77 & 116,38 & - & 2,19 & 30,20 \\
\hline Nísia Floresta & 94,62 & 18,30 & 4,46 & 16,61 & - & 55,86 & 118,00 \\
\hline São Gonçalo do Amarante & 18,23 & 7,55 & 0,36 & 53,48 & 9,26 & 87,61 & 72,87 \\
\hline São José do Mipibu & 139,28 & 0,74 & 0,54 & 15,81 & 9,69 & 45,52 & 79,67 \\
\hline Vera Cruz & 20,24 & 0,14 & 0,09 & 1,58 & - & 44,47 & 17,46 \\
\hline Bom Jesus & 10,70 & 0,67 & - & 2,44 & - & 53,44 & 54,26 \\
\hline Total & 770,70 & 62,50 & 33,01 & 383,38 & 51,85 & 1149,00 & 1223,63 \\
\hline
\end{tabular}

Portanto, diante do significativo incremento da urbanização dos municípios da RMN, a maioria não dispõe do principal instrumento legal cuja função é orientar o processo de ocupação territorial urbano, estabelecendo os mecanismo de gestão e preservação da qualidade ambiental diante dos interesses coletivos e particulares dos habitantes, fatores fundamentais para que a expansão urbana ocorra de modo equilibrado, com estabelecimento de prioridades para cada município, além do conjunta da Região Metropolitana, e dos propósitos de uso do território em perspectiva da sustentabilidade.

Tal fato, revela as integrações de municípios na RMN são apenas a expressão da metropolização institucional, sem a coordenação federativa centralizada e a que conduzisse à governança metropolitana colaborativa (MELQUIORS e CAMPOS, 2016). Portanto, refere-se aos processos legais que culminaram no arranjo metropolitanobrasileiro, em que se estabeleceram, por meio de leis estaduais complementares, sem considerarem a relevânciadafuncionalidade metropolitana (AMBROSIA et al,. 2010). 
FRAZÃO, Ana Paula

AMARO, Venerando Eustáquio

SOUSA, Silvio Braz de

Tabela 4. Porcentagem das classes de uso e cobertura da terra da RMN de 2018 por município

\begin{tabular}{|c|c|c|c|c|c|c|c|}
\hline Município & Agricultura & Água & Dunas & $\begin{array}{c}\text { Mancha } \\
\text { Urbana }\end{array}$ & $\begin{array}{l}\text { Mosaico de } \\
\text { Ocupação }\end{array}$ & Pastagem & Vegetação \\
\hline & \multicolumn{7}{|c|}{$\%$} \\
\hline Arês & 8,64 & 7,04 & 0,09 & 0,36 & 0,52 & 0,51 & 2,64 \\
\hline Ceará-Mirim & 15,2 & 6,54 & 17,1 & 4,85 & 26,12 & 21,34 & 24,57 \\
\hline Parnamirim & 1,36 & 0,15 & 3,59 & 18,81 & - & 0,52 & 2,72 \\
\hline Extremoz & 1,49 & 6,35 & 25,69 & 8,48 & 3,89 & 2,47 & 4,31 \\
\hline Goianinha & 9,7 & 1,8 & 3,65 & 1,39 & - & 5,01 & 4,21 \\
\hline Ielmo Marinho & 8,14 & 1,52 & 0,61 & 0,16 & 6,51 & 7,99 & 12,47 \\
\hline Macaíba & 11,3 & 10,05 & 3,16 & 10,23 & 30,78 & 18,85 & 11,85 \\
\hline Maxaranguape & 1,35 & 7,04 & 17,44 & 0,75 & 0,58 & 1,24 & 7,56 \\
\hline Monte Alegre & 4,69 & 0,89 & 0,74 & 1,17 & 2,96 & 10,27 & 4,1 \\
\hline Natal & 0,62 & 14,8 & 11,4 & 30,36 & - & 0,19 & 2,47 \\
\hline Nísia Floresta & 12,3 & 29,27 & 13,52 & 4,33 & - & 4,86 & 9,64 \\
\hline São Gonçalo do Amarante & 2,36 & 12,08 & 1,08 & 13,95 & 17,86 & 7,62 & 5,96 \\
\hline São José do Mipibu & 18,2 & 1,18 & 1,65 & 4,46 & 16,8 & 3,92 & 6,11 \\
\hline Vera Cruz & 2,63 & 0,22 & 0,28 & 0,41 & - & 3,87 & 1,43 \\
\hline Bom Jesus & 1,39 & 1,07 & - & 0,64 & - & 4,65 & 4,43 \\
\hline Total & 100 & 100 & 100 & 100 & 100 & 100 & 100 \\
\hline
\end{tabular}

Fonte: elaboração autores

Na Figura 5, é possível observar algumas caractetrístias de uso e cobertura encontradas em campo, com áreas de difícil discriminação nas imagens LANDSAT 8-OLI, que são hortaliças em Nisía Floresta, que registrou uma cobertura de $94,62 \mathrm{~km}^{2}$ com cultivares. Observa-se também uma área de pastagem em São Gonçalo do Amarante com reses bovinas, percebe-se a presença de árvores de pequeno porte, uma característica da região e que pode causar confusão no classificador/analista, inteligencia que foi incorporada no processo de classificação para minimizar os erros. Reforça-se que as pastagens estão fotossinteticamente ativas e saudáveis, o que em conjunto com as árvores de pequeno porte, podem produzir um comportamento espectral semelhante a da vegetação do tipo campo.

Figura 5. A) Área de pastagem em Gonçalo do Amarante e B) áreas de agricultura em Nisía Floresta

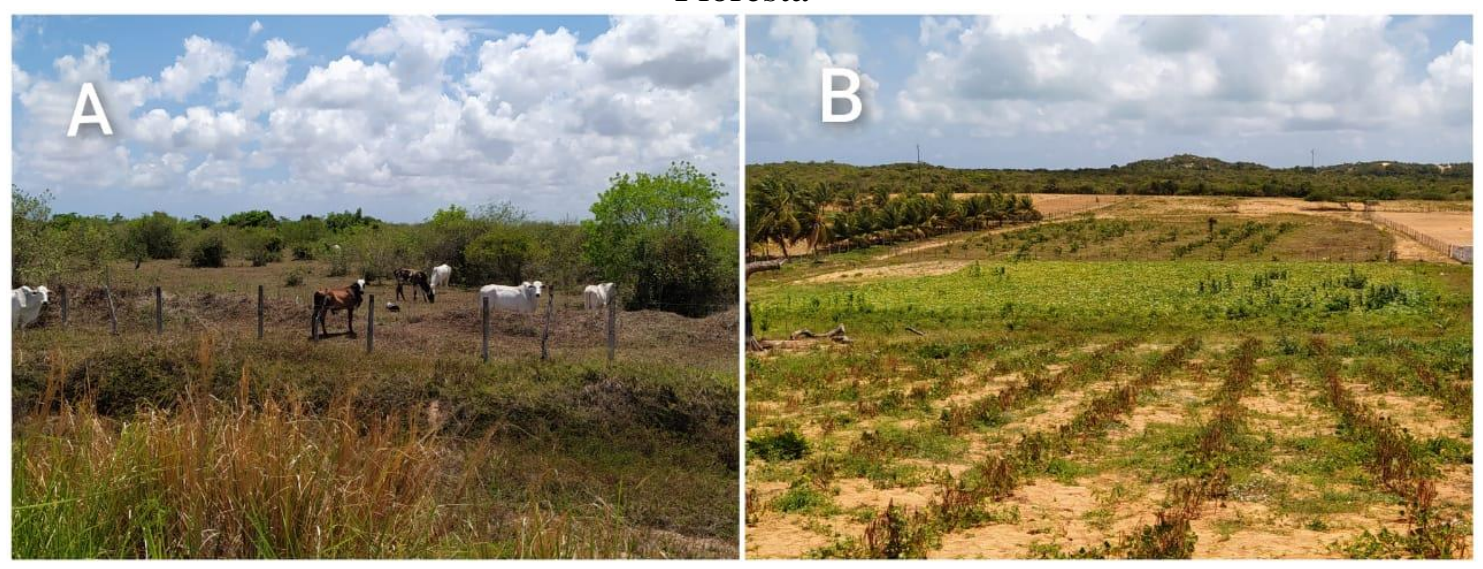

Fonte: Elaboração autores. 
O mapa de uso e cobertura da terra LANDSAT8-OLI do ano de 2018 quando avaliado utilizando como referência 200 pontos adquiridos de forma aleatória na imagem Rapideye, apresentou uma exatidão global de aproximadamente 70\% (Tabela 5). A classe pastagem , que possuiu 74 pontos amostrais, apresentou maior porcentagem de erro, com acurácia de 62\%, sendo muito confudida com vegetação (Tabela 6), registra-se que em algumas áreas da RMN há vegetação com fitofisionomia campestre, o que pode pomover este tipo de mistura (erro de omissão).

Tabela 5. Avaliação das classes de uso e cobertura do mapa 2018 por meio de imagem

Rapideye

\begin{tabular}{|c|c|c|c|c|c|c|c|}
\hline Classe Avaliadas & Agricultura & Água & Dunas & $\begin{array}{l}\text { Mancha } \\
\text { Urbana }\end{array}$ & $\begin{array}{l}\text { Mosaico de } \\
\text { Ocupação }\end{array}$ & Pastagem & Vegetação \\
\hline $\begin{array}{l}\text { Total de pontos } \\
\text { coletados } \\
\text { Validacão }\end{array}$ & 20 & 3 & 1 & 20 & 2 & 74 & 80 \\
\hline Positiva & 14 & 2 & 1 & 20 & 2 & 46 & 55 \\
\hline $\begin{array}{l}\text { Acurácia por } \\
\text { classe }\end{array}$ & $70 \%$ & $67 \%$ & $100 \%$ & $100 \%$ & $100 \%$ & $62 \%$ & $69 \%$ \\
\hline Overall Accuracy & $70 \%$ & & & & & & \\
\hline
\end{tabular}

Fonte: Elaboração autores

A classe agricultura e água, apresentaram 70\% e $67 \%$ de acuária, respectivamente. Por sua vez, as classes dunas com um ponto amostral e mancha urbana com 19 pontos amostrais obtiveram $100 \%$ de acurácia.

Tabela 6. Matriz de Confusão imagem Rapideye vesus classificação de cobertura e uso da terra (2018)

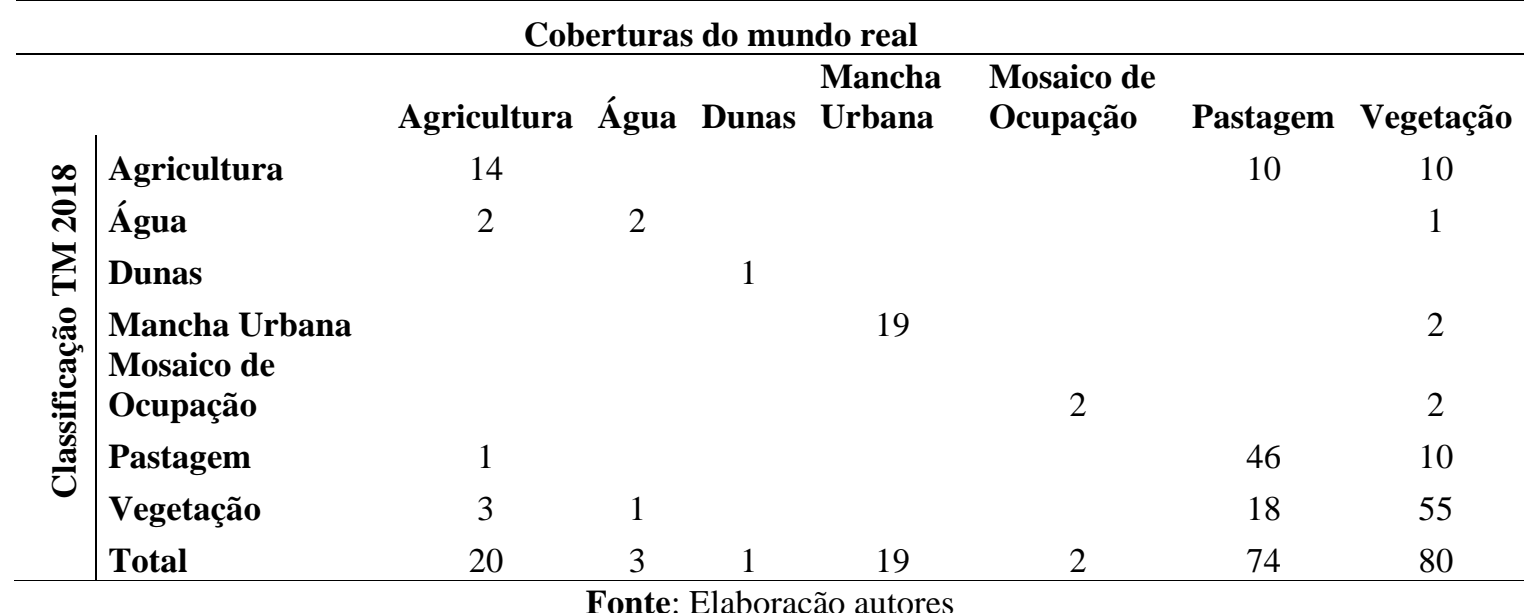

Quando se compara o mapa de uso e cobertura LANDSAT 8-OLI com o conjunto de 150 pontos aleatórios do ortomosaico, registram uma acurácia global de 69\% (Tabela 7). A matriz de confusão para esta avaliação (Tabela 8) a classe vegetação foi que apresentou maior 
erro, tendo 25 pontos confundidos com pastagem, o que garantiu uma acurária para esta classe de apenas $55 \%$.

Tabela 7. Avaliação das classes de uso e cobertura do mapa 2018 por meio de ortomosaicos

\begin{tabular}{|c|c|c|c|c|c|c|c|}
\hline Classe Avaliadas & Agricultura & Água & Dunas & $\begin{array}{l}\text { Mancha } \\
\text { Urbana }\end{array}$ & $\begin{array}{l}\text { Mosaico de } \\
\text { Ocupação }\end{array}$ & Pastagem & Vegetação \\
\hline $\begin{array}{l}\text { Total de pontos } \\
\text { coletados }\end{array}$ & 0 & 0 & 0 & 61 & 0 & 17 & 67 \\
\hline Validação Positiva & 3 & 0 & 0 & 58 & 0 & 6 & 37 \\
\hline Acurácia por classe & $23 \%$ & $0 \%$ & $0 \%$ & $95 \%$ & $0 \%$ & $35 \%$ & $55 \%$ \\
\hline Overall Accuracy & $69 \%$ & & & & & & \\
\hline
\end{tabular}

Fonte: elaboração autores

Tabela 8. Matriz de Confusão entre os ortomosaicos e a classificação de cobertura e uso da terra (2018)

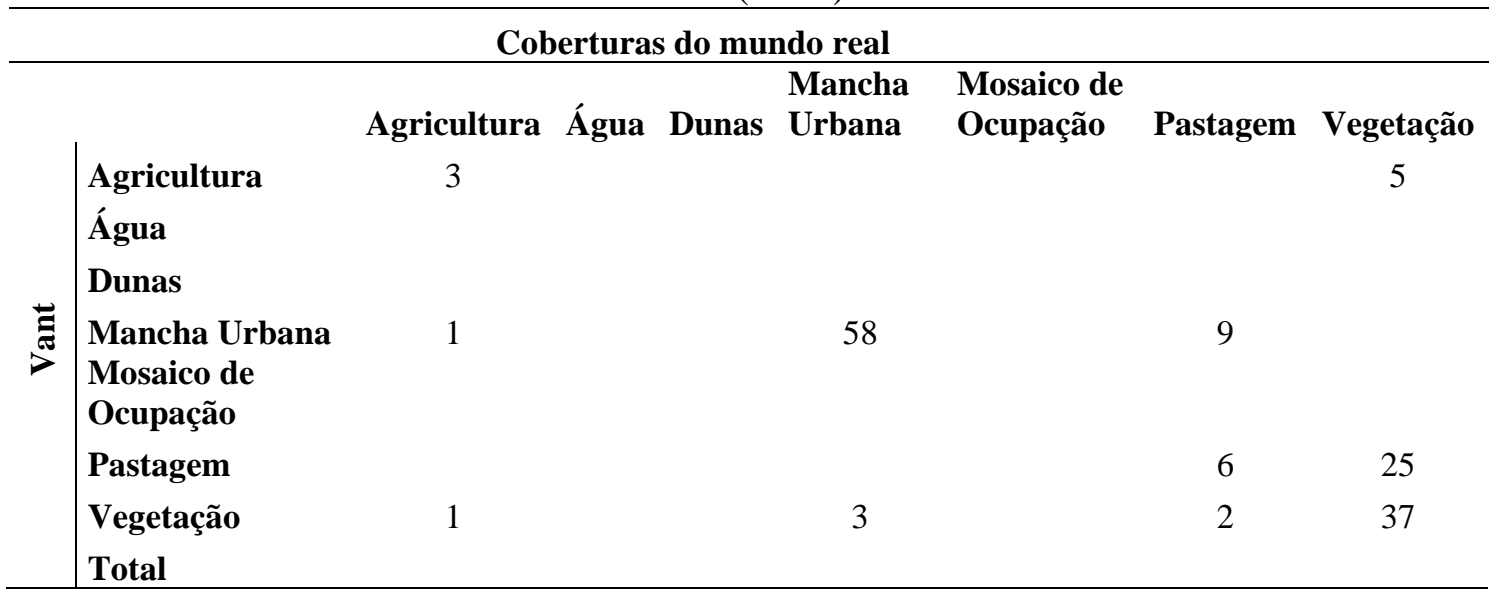

Fonte: elaboração autores

Comparando os quantitativos das áreas ocupadas por pastagem e agricultura com dados do IBGE (2017), e os dados produzidos por esse estudo, podemos observar que a correlação foi adequada (Tabela 9). Os municípios São José do Mipibu, Bom Jesus e Maxaranguape apresentam áreas ocupadas por pastagens similares aos registrados no mapa de uso e cobertura da terra para o ano de 2018, registrando diferença inferior a $5 \mathrm{~km}^{2}$ em área ocupada. A maior discrepancia das áreas de pastagens estão nos municipios de Ceará-Mirim com a diferença de $107,6 \mathrm{~km}^{2}$ e Macaíba com a diferença de $143,7 \mathrm{~km}^{2}$, superiores no mapeamento do OLI Landsat de uso e cobertura deste artigo.

A Figura 6 mostra as áreas de pastagem no ano de 2018 em Ceará-Mirim sobreposta a imagem Rapideye, na qual é possível observar a sinergia entre os dados produzidos e a referencia. Algumas áreas da RMN possuem pastagens em ótimas condições, em meio a vegetação de pequeno porte arbóreo, o que pode gerar misturas na análise e interpretação de 
imagens.

Quanto à classe de agricultura, os municípios com maiores similaridades, ou diferenças inferiores a 4 km², com os dados do IBGE (2017), são Bom Jesus, Extremoz e Maxaranguape. Apesar da área mapeada com a classe agricultura ser maior do que os registros do IBGE (2017) nos municípios de São Jose do Mipibu (maior $85 \mathrm{~km}^{2}$ ) e Nisia Floresta (maior 73,9 km²), podese observar na Figura 7 a área mapeada de agricultura sobreposta na imagemRapideye onde se destaca que os dados LANDSAT8-OLI, estão coerente com as referências.

Tabela 9. Comparação de áreas ocupada $\mathrm{em}^{\mathrm{km}^{2}}$ de agricltura e pastagem segundo o IBGE (2017) e mapa de uso e conertura da terraLANDSAT 8-OLI (2018)

\begin{tabular}{|c|c|c|c|c|c|c|}
\hline \multirow[b]{2}{*}{ Município } & \multicolumn{2}{|c|}{ Agricultura } & \multicolumn{4}{|c|}{ Pastagens } \\
\hline & IBGE & $\begin{array}{c}\text { LANDSAT 8- } \\
\text { OLI }\end{array}$ & $\neq$ & IBGE & $\begin{array}{c}\text { LANDSAT 8- } \\
\text { OLI } \\
\end{array}$ & $\neq$ \\
\hline Arês & 98,3 & 66,6 & -32 & 4,8 & 5,9 & 1,1 \\
\hline Bom Jesus & 14,9 & 10,7 & -4 & 52,8 & 53,4 & 0,6 \\
\hline Ceará-Mirim & 84,7 & 116 & 31 & 137,4 & 245 & 108 \\
\hline Parnamirim & 2,4 & 10,4 & 8 & 0,0 & 6,0 & 6 \\
\hline Extremoz & 8,3 & 11,5 & 3 & 7,1 & 28,5 & 21,4 \\
\hline Ielmo Marinho & 29,4 & 62,7 & 33 & 101,4 & 91,9 & $-9,5$ \\
\hline Macaíba & 52,0 & 87,0 & 35 & 72,3 & 216,6 & 144 \\
\hline Maxaranguape & 12,3 & 10,4 & -2 & 19,8 & 14,2 & $-5,6$ \\
\hline Monte Alegre & 20,2 & 36,1 & 16 & 72,8 & 118,0 & 45,2 \\
\hline Natal & 0,3 & 4,8 & 4,5 & 0,5 & 2,2 & 1,4 \\
\hline Nísia Floresta & 20,7 & 94,6 & 74 & 18,9 & 55,9 & 37 \\
\hline São Gonçalo do & & & 8 & & & 43 \\
\hline Amarante & 10,4 & 18,2 & & 44,5 & 87,6 & \\
\hline São José de Mipibu & 53,3 & 139 & 86 & 40,5 & 45,5 & 5 \\
\hline Vera Cruz & 17,2 & 20,2 & 3 & 29,2 & 44,5 & 15 \\
\hline Goianinha & 73,4 & 74,7 & 1,3 & 35,7 & 57,6 & 21,9 \\
\hline Total & 497,6 & 761,88 & & 637,6 & $1.079,7$ & \\
\hline
\end{tabular}

Elaboração: autores. 
FRAZÃO, Ana Paula

AMARO, Venerando Eustáquio

SOUSA, Silvio Braz de

Figura 6. Áreas ocupadas por pastagem no município de Ceará-Mirim
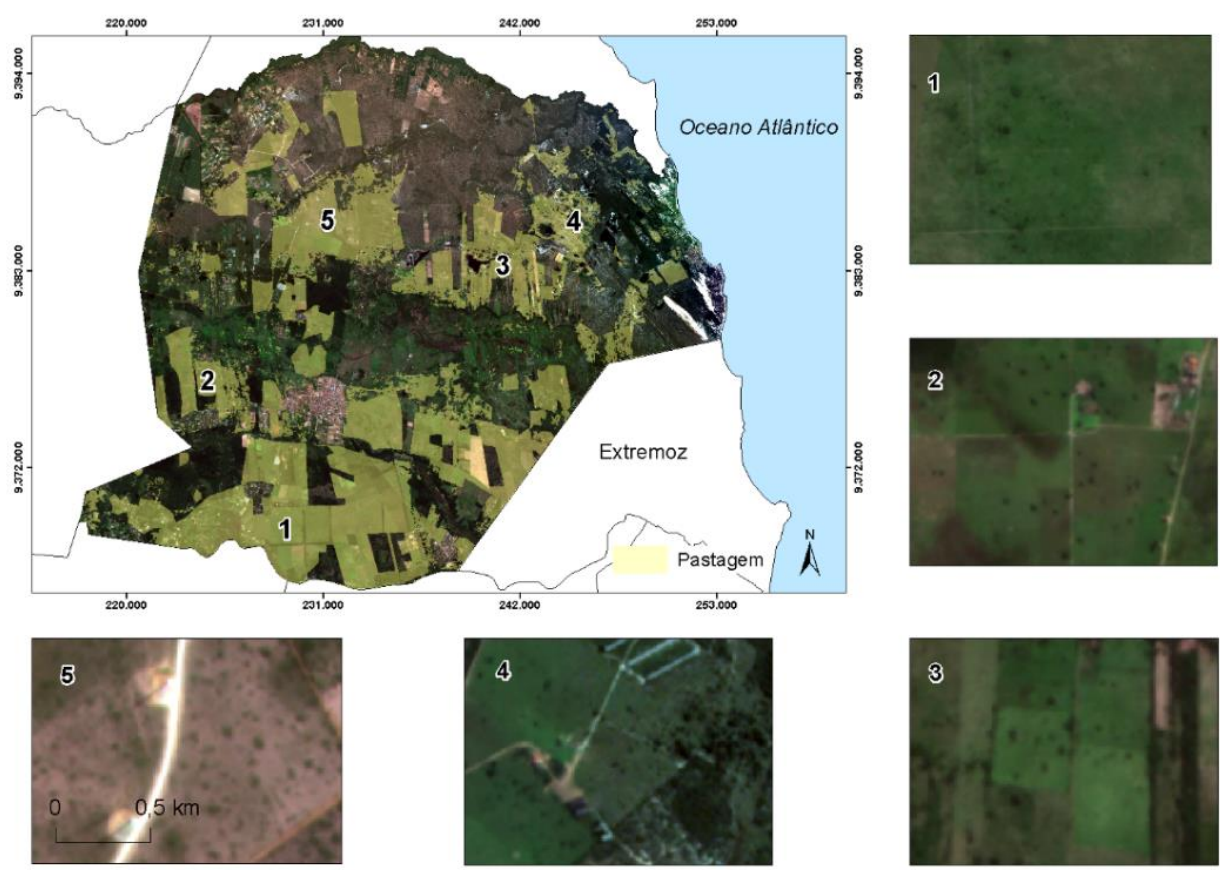

Fonte: Elaboração autores

Figura 7. Áreas ocupadas por agricultura no município de São José do Mipibu
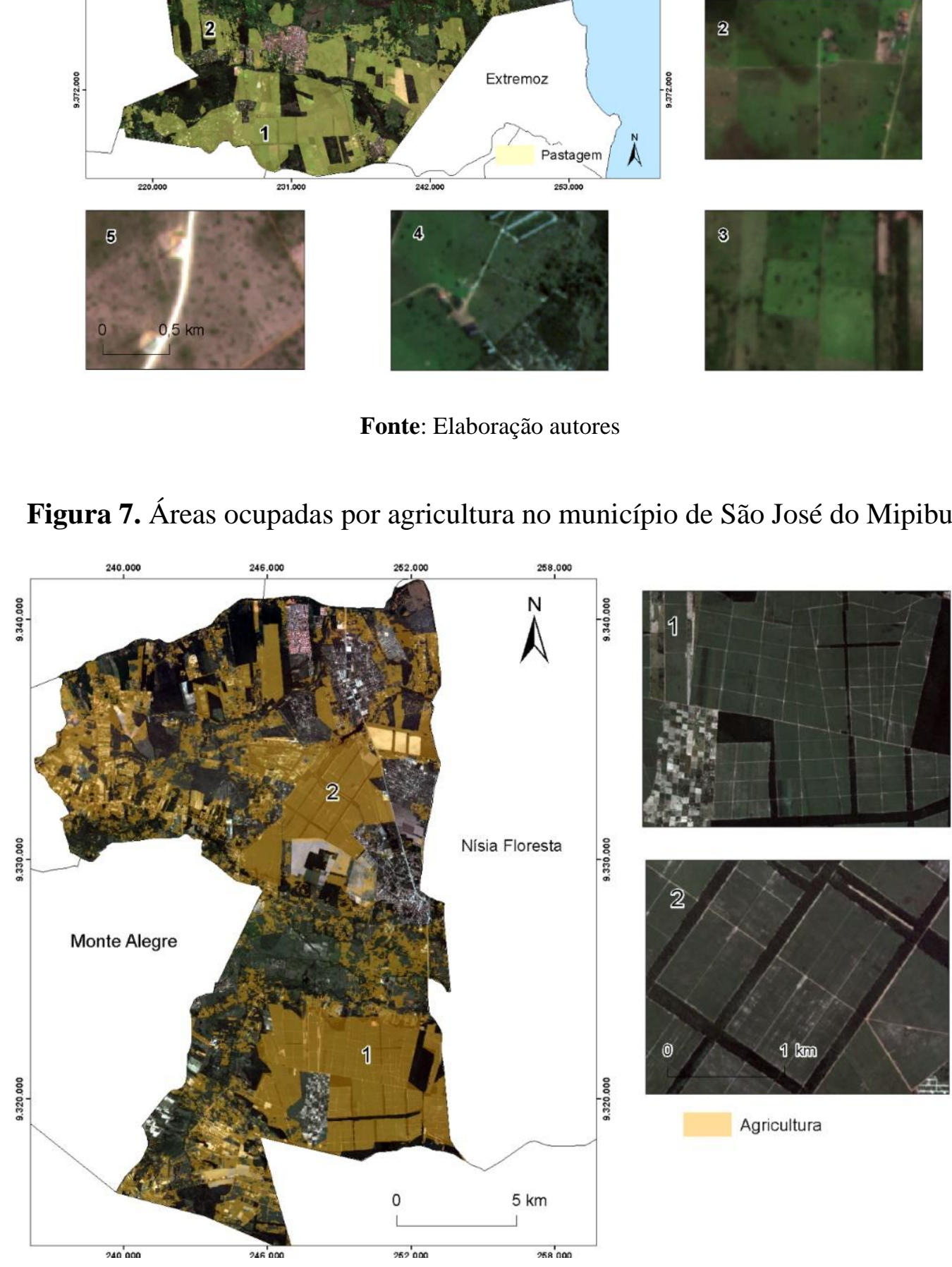

Agricultura

Fonte: Elaboração autores 


\section{CONSIDERAÇÕES FINAIS}

Esse artigo buscou analisar o uso e cobertura da RMN no ano de 1984 e 2018, por meio de diversos dados (orbitais e estatísticos). Os resultados levantados sobre o uso e cobertura da terra nos quinze municípios que compõe a $\mathrm{RMN}$, confirmam intensa e rápida conversão das áreas de vegetação (redução de $\sim 1.402 \mathrm{~km}^{2}$ ) e sua apropriação para atividades antrópicas, predominantemente de agropecuária. Também se constatou um processo de urbanização bastante expressivo, principalmente nos municípios limítrofes a Natal, com destaque para Parnamirim, Extremoz e São Gonçalo do Amarante, que juntamente com Natal somam uma mancha urbana de $274 \mathrm{~km}^{2}, 71 \%$ de toda mancha urbana da RMN. Demais municípios da RMN, não possuem grande expressividade urbana, tais como Vera Cruz, Bom Jesus e Âres, que somam apenas $5,4 \mathrm{~km}^{2}, 1,4 \%$.

Dessa forma, se conclui que a metropolização da RMN foi institucional e que boa parte desses municípios não possuem planejamento, já que a maior parte delesnão possuem planos diretores ou estão com os planos diretores desatualizados. Apesar disso, percebemos como os municípios cresceram sua mancha urbana após serem integrados a RMN. Além disso, registrou-se que os municípios que não possuem uma mancha urbana expressiva, obtiveram expansão das coberturas agropecuárias.

Quanto as contribuições para o emprego do Sensoriamento Remoto e do Geoprocessamento na elaboração de mapas de uso e cobertura da terra, destaca-se o sinergismo observado entre as imagens multiespectrais utilizadas, fato primordial para o entendimento e redução de erros inerentes aos mapeamentos em escala de 1:100.000. Também confirmou o excelente desempenho operacional das imagens orbitais da sérieLANDSATem mapeamentos das mudanças no uso e cobertura da terra em área de abrangência regional.Outra contribuição foi mostrar a eficiencia das imagens Rapideye, para avaliação e validação de mapas de uso e cobertura da terra realizados com base em dados de maior catálogo temporal, no entanto, pior resolução espacial.

Além disso, tais dados desde que corrigidos e avaliados podem ser aplicados no detalhamento e refinamentode informações ambientais. Cabe ressaltar, que as imagens do satélite Rapideye são comerciais e, portanto, não possuem acervo temporal consistente como a série de satélites LANDSAT. De fato, tais dados foram disponbilizados de forma circunstancial, haja vista a emergêcnica de uma preocupação global com os desmatamentos em florestas tropicais no ano de 2020, o que confirma os dados da série LANDSATcomo as principais bases 
FRAZÃO, Ana Paula

AMARO, Venerando Eustáquio

SOUSA, Silvio Braz de

cartográficas para mapeamento sistemático de uso e cobertura da terra em contextos regionais.

A formalização das RMs surgiram com o intuito de para integrar a organização, o planejamento e a execução de funções públicas de interesse comum (FERNDES e ARAUJO, 2015). Dessa forma, é importante ressaltar que é necessário uma ação conjunta entre os municipios das RM, para a resolução de grande parte das questões urbanas, como transporte, abastecimento de água, crescimento urbano e uso do solo, pois geralmente extrapolam a esfera municipal sendo compartilhadas por cidades integrantes das algromerações, demando soluções integradas (MELCHIORS e CAMPOS, 2016).

Sendo assim, os probelmas causados pelo uso e cobertura da terra, indicam a falta de politicas integradas e colaborativas de gestão nos municípios que formam a RMN.

\section{REFÊRENCIAS}

\section{AMARO V. E. et al. Avaliação da Suscetibilidade do Solo à Erosão nas Falésias do}

Litoral Oriental do Estado do Rio Grande do Norte. Rev. Bras. Geomorfol. (Online), São Paulo, v.22, n.1, (Jan-Mar) p.03-25, 2021. http://dx.doi.org/10.20502/rbg.v22i1.1887

AMBROSIS, C de.Regiões metropolitanas, aglomerações urbanas e microrregiões. In: MOREIRA, M. (org.) Estatuto da cidade. São Paulo: Fundação Prefeito Faria Lima,CEPAM, 2001.

BARAU, A.S.; LUDIN, A.N.M. Intersection ofLandscape, Anthropocene and Fourth Paradigm. Living Reviews in Landscape Research, 2012.

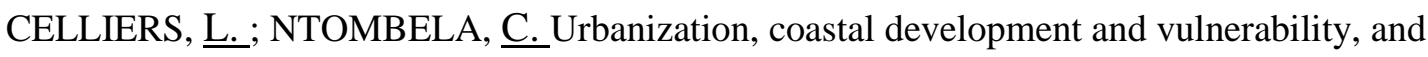
catchments. Regional State of the Coast Report,p. 386-404, 2016.

http://dx.doi.org/10.18356/cd2f1dd6-en

CREEL, L. Ripple Effects: Population And Coastal Regions. Population Reference Bureau

GIRI, C. Remote Sensing of Land Use and Land Cover.CRC Press, Taylor \& Francis, 2012, 469pp.

DEWAN, A. M., YAMAGUCHI, Y. Land use and land cover change in Greater Dhaka, Bangladesh: Using remote sensing to promote sustainable urbanization.Applied Geography, v. 29, n. 3, p. 390-401, 2009. http://dx.doi.org/10.1016/j.apgeog.2008.12.005 
FERNANDES, A. S.. A., ARAÚJO, S. M. V. G.A criação de municípios e a formalização de regiões metropolitanas: os desafios da coordenação federativa.urbe, Rev. Bras. Gest.

Urbana, vol.7, n.3, pp.295-309, 2015.

GROSTEIN, M. D. Metrópole e Expansão Urbana: A Persistência de Processos

"Insustentáveis". São Paulo Perspec., São Paulo, v. 15, n. 1, p. 13-19, Jan. 2001. https://doi.org/10.1590/S0102-88392001000100003.

HARLEY, J. B., Woodward, D. eds. Cartography in Prehistoric, Ancient, and Medieval Europe and the Mediterranean. Vol. 1 of The History of Cartography. Chicago:

Universityof Chicago Press, 1987.

IBGE - Instituto Brasileiro de Geografia e Estatística. Censo Agropecuário 2018: resultados. Disponível em:

http://www.ibge.gov.br/home/estatistica/economia/agropecuaria/censoagroAcesso em: $26 \mathrm{de}$ dezembro 2020.

LAI, S. et. al.The effects of urbanization on coastal habitats and the potential for ecological engineering: A Singapore case study.Ocean \& Coastal Management, n. 103, 78-85, 2015.http://dx.doi.org/0.1016/j.ocecoaman.2014.11.006

LAMBIN, E. F. et al. Estimating the world's potentially available cropland using a bottom-up approach. Global Environmental Change, v. 23, p. 892-901, 2013.https://doi.org/10.1016/j.gloenvcha.2013.05.005

LE, T. D. N. Climate change adaptation in coastal cities of developing countries: characterizing types of vulnerability and adaptation options.Mitigation and Adaptation Strategies for Global Change, n. 25, p. 739-761, 2019. http://dx.doi.org/10.1007/s11027$\underline{019-09888-\mathrm{Z}}$

LONG, H. et. al. Socio-economic driving forces of land use change in Kunshan, the Yangtze River Delta economic area of China.Journal of Environmental Management, v. 83, p. 351364, 2007.https://doi.org/10.1016/j.jenvman.2006.04.003

LOPEZ, E.et. al. Predicting land cover and land use change in the urban fringe a case in Morelia City, Mexico.Landscape and Urban Planning, v. 5, n. 4, 271-285, 2001. https://doi.org/10.1016/S0169-2046(01)00160-8

LOURENÇO, L. F. A.Metrópoles, cobertura vegetal, áreas verdes e saúde. Estudos Avançados, v. 30, n.86, 2016.

MELCHIORS, C. L. , CAMPOS, A. H. As regiões metropolitanas brasileiras no contexto do Estatuto da Metrópole: Desafios a serem superados em direção à governança colaborativa Revista Política e Planejamento Regiona, v. 3, n. 2, p. 181- 203, 2016

MOREIRA, A. M. L. Regiões Metropolitanas na Constituição Estadual. Adaptação do 
documento O Município e a Questão Urbana. Sugestões para a Constituição do Estado de São Paulo. São Paulo: Fundação Prefeito Faria Lima, CEPAM, 1989.

PBMC, Painel Brasileiro de Mudanças Climáticas. Impacto, vulnerabilidade e adaptação das cidades costeiras brasileiras às mudanças climáticas: Relatório Especial do Painel Brasileiro de Mudanças Climáticas [Marengo, J.A., Scarano, F.R. (Eds.)]. PBMC, COPPE - UFRJ. Rio de Janeiro, Brasil. 184 p., 2016.

SINGH, Y. Significance of Land Use / Land Cover (LULC) Maps. Satpalda Geospatial Service, 2015. Disponível em: https://www.satpalda.com/blogs/significance-of-land-use-landcover-lulc-maps Acesso em 05/02/2021

THAKUR, J. K.et. al. Geospatial Techniques for Managing Environmental Resources. Editora Springer, New York - USA, 2011.

YIN, J.et. al. Monitoring urban expansion and land use/land cover changes of Shanghai metropolitan area during the transitional economy (1979-2009) in China.Environmental Monitoring and Assessment, v. 177, n. 1-4, p. 609-621, 2010.

http://dx.doi.org/10.1007/s10661-010-1660-8

ZHANG, Q.;SETO, K. C. Mapping urbanization dynamics at regional and global scales using multi-temporal DMSP/OLS nighttime light data. Remote Sensing of Environment, v. 115, n.9, p. 2320-2329, 2011. http://dx.doi.org/10.1016/j.rse.2011.04.032

MENDOZA, M.E; GRANADOS, E.L.; GENELETTI, D.; PÉREZ-SALICRUP, D. R;

SALINAS, V. Analysing land cover and land use change processes at watershed level: A multitemporal study in the Lake Cuitzeo Watershed, Mexico. Applied Geography 31(1), 237-250, 2011.

SANHOUSE-GARCIA, A. J.; BUSTOS-TERRONES, Y.; RANGEL-PERAZA, J. G.; QUEVEDO-CASTRO, A.; PACHECO, C. Multi-temporal analysis for land use and land cover changes in an agricultural region using open source tools. Remote Sensing

Applications: Society and Environment, 8:278-290, 2017.

Recebido em 21 de fevereiro de 2021

Aceito em 02 de março de 2021

Publicado em 07 de abril de 2021 